\title{
ecalogmatzidis open access \\ OSTEOARTHRITIS AS AN ORGAN DISEASE: FROM THE CRADLE TO THE GRAVE
}

\author{
R.M. Aspden*, F.R. Saunders \\ Aberdeen Centre for Arthritis and Musculoskeletal Health, University of Aberdeen
}

\begin{abstract}
Considered for decades as a cartilage disease, recent studies of osteoarthritis (OA) take us back to the concepts discussed at the naming of the disorder as "bone-joint-inflammation". By describing the joint as an organ, can OA be called an organ disease - similar to heart disease? Is there a systemic (which system?) involvement? Would this help with diagnosis or therapy? Hyperplasia of the joint tissues is one of the most notable early features of the disease: articular cartilage thickens, chondrocytes proliferate and increase matrix biosynthesis, but not its incorporation; the subchondral bone densifies but is hypomineralised and there is an increase in bone marrow fat content. Associations between OA and hypertension, hypercholesterolaemia and blood glucose suggest systemic and metabolic components are involved. The source of pain is still unknown but there is evidence for peripheral and central sensitisation. Joint deformity is difficult to quantify, but statistical shape modelling provides a tool to use as an imaging biomarker. A genome-wide association study metaanalysis has identified novel genes associated with hip shape with many genes related to tissue growth and development. There are associations between hip shapes and age of first walking as well as with obesity through adulthood. These life-course events and a recapitulation in old age of developmental processes suggest that the cradle may affect our path to the grave. These observations suggest that tissue regeneration approaches, treating only the cartilage in OA joints, may only be of limited benefit.
\end{abstract}

Keywords: Osteoarthritis, joint, systemic disease, metabolic disease, aetiology, growth, hyperplasia, development.

*Address for correspondence: Prof. Richard M. Aspden, Arthritis and Musculoskeletal Medicine, School of Medicine, Medical Sciences and Nutrition, University of Aberdeen, Aberdeen, AB25 2ZD, UK Telephone number: +4401224 437445 Email: r.aspden@abdn.ac.uk

Copyright policy: This article is distributed in accordance with Creative Commons Attribution Licence (http://creativecommons.org/licenses/by-sa/4.0/).

\section{Introduction}

Osteoarthritis (OA) has been considered for many decades as a disorder of articular cartilage arising from "wear and tear". However, recent studies appear to be taking us back to the concepts considered at the naming of the disorder as osteo-arthr(o)-itis; "bonejoint-inflammation". The recent review by Dobson and colleagues on the naming of "osteoarthritis" (Dobson et al., 2018) attributes the name to surgeon Richard von Volkmann in the mid-nineteenth century to distinguish the disorder from rheumatoid arthritis (RA) and gout. Others suggest that Garrod originated the term in 1890 and he certainly popularised it in the 1907 edition of Albutt and Rolleston's System of Medicine in which he describes separately these disorders (Garrod, 1907). Garrod was also a surgeon and his observations of the joint in the operating theatre led him to support the idea of a whole joint disorder associated with inflammation and, interestingly, he also suggested that the central nervous system played a key role. Cartilage was, seemingly, not considered to be important. By the 1950s, with the advent of more sophisticated methods for biochemical analysis and, later, molecular biology, cartilage became the dominant tissue of interest and very little was made of the subchondral bone or other joint tissues. Although there are some papers from over 25 years ago advocating that $\mathrm{OA}$ is whole joint disease the idea had not gained much traction until recently when there has been a shift in thinking in the osteoarthritis research community. There has been a refocusing from solely cartilage-based studies to contemplating the whole joint and the associated tissues as a whole-joint disorder and considering the interactions between the soft tissues and the mineralised tissues. This is reflected in the increased number of papers including soft tissues in their studies, thus returning full circle to ideas laid out by Garrod over a hundred years ago. Whilst the number 
of papers focusing on cartilage has not decreased, there is an increased number of papers that deal with other aspects of osteoarthritis pathology, including soft tissue interactions with cartilage and mineralised tissue.

Some forms of OA follow trauma and affect a single joint, an abnormal load on a normal joint. Most, however, are still classed as idiopathic - unknown cause - and are polyarticular in nature. Traditionally, idiopathic OA has been suggested to arise from normal loads on abnormal cartilage or from abnormal loads on normal cartilage. In both of these scenarios, the abnormality is often much more elusive than an obvious traumatic incident. Curiously, hand OA is one of the most prevalent forms of OA, affecting around $35 \%$ of adults (Haugen et al., 2011) and hands are rarely subject to abnormal loads, suggesting some other cause. Despite the history of the name described above, the emphasis in recent decades has largely been on the articular cartilage of the synovial joints as the affected tissue and biomechanical factors as the causative agents. Changes in other tissues have been treated as secondary, including alterations to subchondral bone and other tissues believed to arise from secondary inflammation and enforced inactivity.

In some recent publications, it is proposed that the joint should be considered as an organ (Loeser et al., 2012; Lories and Luyten, 2010; Radin et al., 1991). Can OA, therefore, be described as an organ disease in a similar way to heart disease? Is there a systemic involvement and, if so, by which system or systems? Does this help with diagnosis or therapy? Indeed, does this view complicate the treatment of $\mathrm{OA}$ ? In this review the effects of OA on a number of joint tissues were examined and an attempt made to show that, although "cartilage first" cannot be ruled out, it is not the only, - or even necessarily the best - explanation for the hyperplasia observed in many tissues forming the joint. Similarly, although biomechanics almost certainly plays an important role in the progression of the disease, its part in the incidence of primary generalised OA is less clear. It may be the factor that determines, in any individual, which joint displays the first signs; however, the working hypothesis was that generalised OA is a recapitulation or renewing of growth processes that should have ceased permanently at the end of development and that these are driven by metabolic and systemic factors.

It is proposed that $\mathrm{OA}$, at least in its generalised form, is a systemic musculoskeletal disease, further developing ideas presented previously (Aspden, 2008; Aspden, 2011; Aspden et al., 2001). Specifically, it is suggested that OA is characterised by dysregulated growth of musculoskeletal tissues and that many of the cells appear to have reverted to an earlier developmental phenotype. The outcome is new tissue being formed in the wrong place and at the wrong time, matrix components not being properly incorporated and a resulting loss of the mechanical properties required for normal function. Initially a discussion of articular cartilage is presented, as this is largely the focus of tissue repair strategies, before considering some of the other tissues comprising the joint.

\section{Articular cartilage}

Cartilage loss is one of the most obvious radiographic signs, often described as "joint space narrowing". On a radiograph the bone is opaque and the cartilage is transparent. If this remarkably smooth load-bearing surface is lost, joint function will be compromised as the bones are forced closer together and ultimately touch - rubbing together. Several significant structural changes result, such as the loss of the low friction environment, increased sensations of pain as innervated bones rub together and, therefore, changes in the bone and functional impairment. The loss of cartilage, however, is a late event that occurs after more subtle structural and molecular changes in both the bone and the articular surfaces and is accompanied by a chronic, low-grade inflammation. This is in direct contrast to the pathophysiology of RA where the primary initiating factor is inflammatory in nature and the changes in cartilage and bone are secondary (Thysen et al., 2015).

The role of the chondrocyte in articular cartilage is extensively reviewed (Goldring, 2000b; Goldring and Goldring, 2007). Essential features of the process often described as degeneration are tissue swelling, cell proliferation, fibrillation and finally erosion. The first observable sign is swelling of the tissue as it absorbs more water (Maroudas, 1976; Wang et al., 2008). This is accompanied by renewed cell division (Mankin et al., 1981), or cloning, of the chondrocytes within their chondron, producing multiple cells where in normal tissue there are typically only 2-4 chondrocytes (Mankin et al., 1981; Poole, 1997). Synthesis of the principal matrix molecules increases (Goldring and Goldring, 2007), including collagen type II (Aigner et al., 1997) and aggrecan (Roughley and Mort, 2014). In the very early stages of the disease, when only minor surface fibrillation is apparent, there is substantial release of aggrecan fragments. However, the net tissue concentration of aggrecan does not decrease (reviewed by Heinegard and Saxne, 2011), indicating that much of this new material appears to be lost rapidly to the joint cavity. Hence, one of the markers for increased tissue turnover is elevated levels of aggrecan fragments in the synovial fluid (Lohmander et al., 1999; Roughley and Mort, 2014). There are also reports of substantial increases in the abundance of cartilage oligomeric protein (COMP) and cartilage intermediate layer protein CILP-1. These new accumulations occur close to the chondrocytes (Lorenzo et al., 2004). It is reported that the altered distributions of these two proteins present a typical and distinct hallmark of the cartilage in the early osteoarthritic 
process. This is the result of molecules being lost from one compartment, through degradation, and accumulating in another as a result of new synthesis (Heinegard and Saxne, 2011). It is also reported that this distinctive distribution is similar to that found during embryonic development (Heinegard and Saxne, 2011; Shen et al., 1995). Interestingly, the expression of collagen type II changes from type IIB, the adult form, to type IIA - a splice-variant that is normally expressed during development (Aigner et al., 1999). Work from Bruce Caterson's lab shows that there are specific epitopes of chondroitin sulphate (4-C-3, 7-D-4 and 3-B-3(-)), more commonly found in foetal tissue, decorating the cell surface proteoglycans on activated stem cells. This could be a signal that these cells are a target for tissue development (Hayes et al., 2018). The significance of these specific epitopes is that they are commonly found on progenitor cells, which occur in increased numbers in OA tissue. This provides further evidence of a reversion to a more developmental-like phenotype. Increased matrix synthesis is accompanied by increased biosynthesis of matrix metalloproteases (MMPs), prostaglandins and other inflammatory factors. These may arise from elevated levels of interleukin IL-1 and tumour necrosis factor TNF $\alpha$ (Goldring, 2000a; Goldring, 2000b; Zhuo et al., 2012). An increase in the pro-inflammatory precursor arachidonic acid, and other lipids, is also reported to be associated with histological severity of OA (Lippiello et al., 1991). Finally, the tidemark - which marks the junction between calcified and uncalcified cartilage - is duplicated and advances into the previously uncalcified tissue (Oettmeier et al., 1989; Radin et al., 1991). This is another indicator of renewed growth and tissue formation, though the underlying mechanisms are still unknown. A stereological study reports an increase in the area covered by the tidemark, with a greater number of blood vessels crossing it, that is taken to be indicative of a vascular involvement in the pathology (Bonde et al., 2005). This feature is quite difficult to model in animals due to the differences in OA pathology of cartilage structure, particularly in rodents. However, there is an in vitro co-culture model of osteoblasts and chondrocytes that can be used to model the changes in the tidemark (reviewed by Thysen et al., 2015) and a model in dogs (Daubs et al., 2006).

Articular cartilage may be considered as a biological fibre-composite material in which collagen fibrils provide tensile reinforcing to a highly hydrated proteoglycan gel (Aspden, 1994). Viewed in this way, it is the interactions between collagen and the other components that provide mechanical integrity (Aspden, 1994; Burgin et al., 2014; Hukins et al., 1984; Lewis et al., 1998) - not simply a stiff collagen 'network' and a filler. The organisation of the fibrils (Aspden and Hukins, 1981; Jeffrey and Aspden, 2006), the electrostatic properties of the gel (Dean et al., 2003; Seog et al., 2002) and interactions between the fibrils and the gel (Aspden, 1994; Rojas et al., 2014) are tightly regulated during development and in response to a changing loading environment to produce appropriate mechanical properties. Proteoglycan turnover, but not collagen turnover (Heinemeier et al., 2016), then maintains the mechanical stability of the tissue. The carbon-14 bomb dating method used by Heinemeier et al. (2016) demonstrates the relative stability of the collagen structure in both healthy and diseased tissue. Page Thomas and colleagues demonstrate, in rabbits, that - after an immediate extensive loss of proteoglycans from cartilage - there is suppression of the production in the immediate aftermath of injury but this then doubles its rate after one week (Page Thomas et al., 1991). Excess synthesis of new matrix and a reversion of the chondrocytes to a developmental-like phenotype could weaken the tissue by inappropriate remodelling. Weakening of the tissue in this way could then make it susceptible to mechanical damage. Even in elderly tissue, chondrocytes respond to mechanical (Plumb and Aspden, 2005) and chemokine stimuli (Plumb et al., 2006) and to tissue damage (Jeffrey et al., 1997). However, once the tissue structure, especially the collagen organisation, has been lost it does not presently seem possible to restore it. Catterall and colleagues show that the half-life of collagen is very long, in excess of 100 years; therefore, the loss of collagen appears to be irreversible (Catterall et al., 2016). Studies of mechanical loading, on elderly human articular cartilage, indicates that both cyclic and static loads inhibit matrix macromolecule biosynthesis (Plumb and Aspden, 2005) and could over-ride the normally stimulatory effect of IGF-1 (Plumb et al., 2006; Wheeler et al., 2009). This differs from results from young bovine tissue where cyclic load is generally found to be stimulatory (Guilak et al., 1994; Larsson et al., 1991; Palmoski and Brandt, 1984; Sah et al., 1989). Supporting this, preliminary gene expression studies comparing OA cartilage with that obtained from hip fracture patients indicated that cyclic loading produced no changes in gene expression for matrix macromolecules at greater than a 4-fold level but that there were changes in the expression of growth factors (FGF-18, FGF-2, VEGF and WNT16), all of which promote chondrocyte division, and molecules associated with increased matrix turnover such as COX-2 and ADAMTS-1 (Meeting abstract: Plumb and Aspden. Osteoarthritis Cartilage 2005 13: S104.).

\section{Bone}

A number of signs of OA appear in the bones forming the joint. These include sclerosis of the subchondral bone, the formation of so-called "cysts" in the trabecular bone, and osteophytosis. Cysts are cavities in the cancellous bone, often found in late-stage OA below the loaded articulating region (Havdrup et al., 1976). The mechanism of cyst formation is still unclear. Recent studies favour the idea of bone contusion over synovial fluid intrusion, due to their 
association with bone marrow lesions seen using magnetic resonance imaging (MRI) (Carrino et al., 2006; Crema et al., 2010). Irrespective of how they are initiated, removal of so much bone suggests significantly increased osteoclastic activity (Havdrup et al., 1976). In contrast, osteophytes are outgrowths of bone and cartilage found in many patients at the margins of diarthrodial joints or as outgrowths in the central portions of the articular space in about $15 \%$ of patients (McCauley et al., 2001), as well as in the spine, around zygoapophyseal joints and vertebral bodies particularly in the lumbar region (Klaassen et al., 2011). Osteophytes form by endochondral ossification (Gelse et al., 2003). The latter process shows many similarities to bone formation during development and the signalling pathways activated during osteophyte formation are shown to be similar to those found in callus formation during fracture repair (Arden and Nevitt, 2006; Patel et al., 2003; van der Kraan and van den Berg, 2007). Bone usually adapts in response to mechanical loading and growth of new tissue, in the absence of such a stimulus, requires other causes. One suggestion is that TGF- $\beta$ could provide this signal (Scharstuhl et al., 2002; van Beuningen et al., 1994). Similarly, subchondral sclerosis has traditionally been regarded as a reaction to increased load following cartilage loss. Several studies, however, indicate that bone changes are evident concurrently with cartilage fibrillation (Dedrick et al., 1993) or that sclerosis is evident radiographically before joint space narrowing (Buckland-Wright et al., 1995).

Patients with radiographic OA of the hip are reported to have an elevated bone mineral density not only in the hip but also in the distal radius, vertebrae and calcaneus (Nevitt et al., 1995). Scintigraphy, using technetium $99 \mathrm{~m}$, shows increased bone forming activity in joints with pathological signs of OA (Buckland-Wright et al., 1995). Laboratory studies show alterations in the bone matrix and in osteoblast behaviour. In the hip, an increase in cancellous bone volume of about $60 \%$ was found but this was associated with a reduced mineralisation (Li and Aspden, 1997a). Using back-scattered as well as secondary emission electron microscopy, the appearance of the cancellous bone was found to be similar to woven bone seen in fracture repair ( $\mathrm{Li}$ et al., 1999) with evidence of osteoclastic resorption in the form of Howship lacunae. In addition, although the subchondral bone plate was thicker, it too was less well mineralised (Li and Aspden, 1997b) (Fig. 1 ). Increased amounts of bone are reported in the iliac crest of patients with OA of the hand (Gevers et al., 1989a; Gevers et al., 1989b), together with greater levels of growth factors (Dequeker et al., 1997) - supporting the concept that OA may be a part of a generalised disorder. Among the anabolic factors identified as important in bone formation

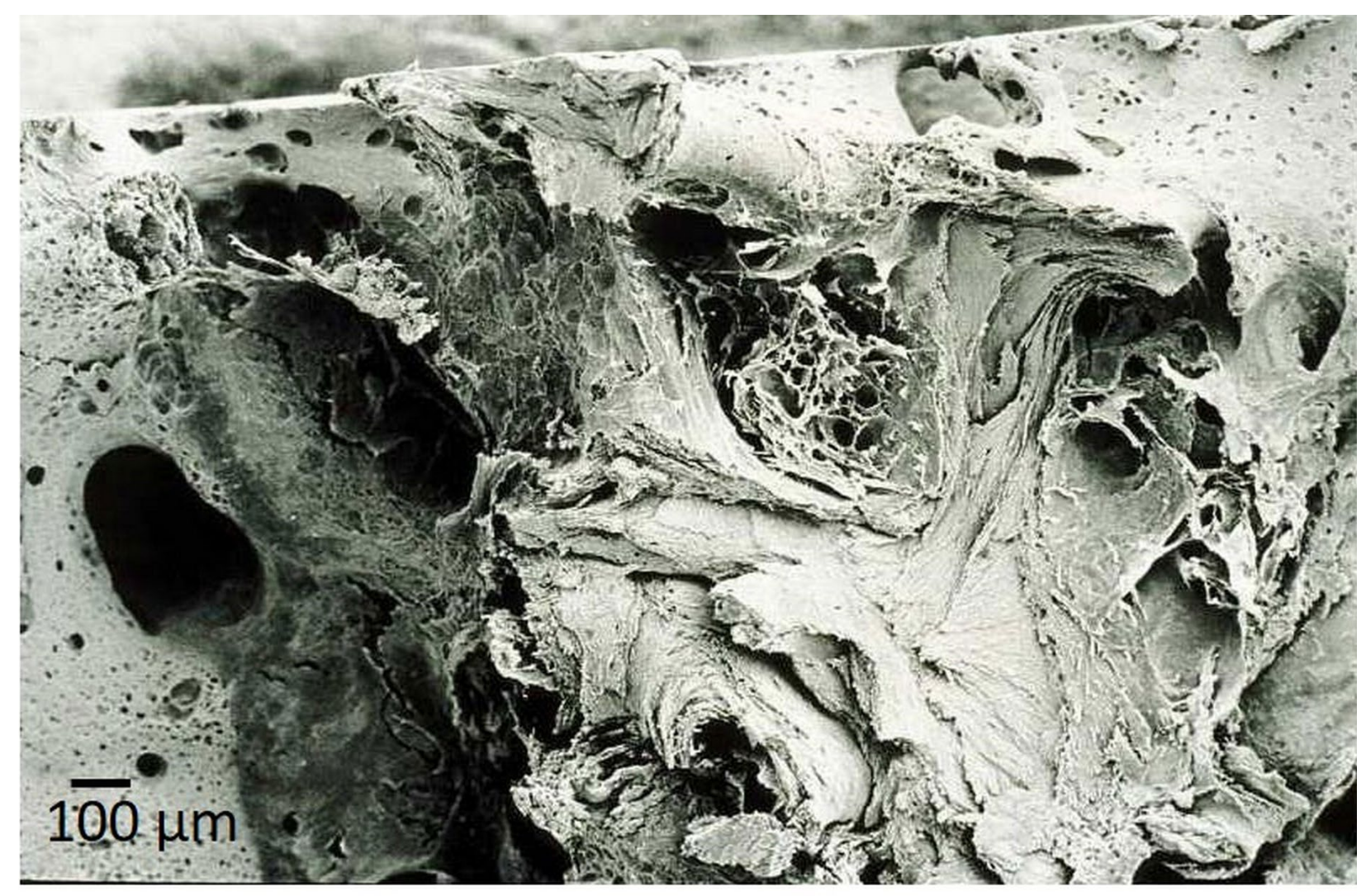

Fig. 1. Scanning electron micrograph of subchondral bone from a 75-year-old patient following total hip replacement for $\mathbf{O A}$. The porous and coarse texture of the bone matrix is apparent, and measurement showed the matrix to be hypomineralised. 
are the Wnt family and several studies show their differential regulation in OA (Burr and Utreja, 2018; Corr, 2008; Luyten et al., 2009). In a preliminary gene expression study, not only was differential regulation of some of the more obvious members of Wnt signalling pathways found but that the most differentially regulated gene was that for NHERF1 (Sodium/hydrogen exchange regulatory cofactor 1; SLC9A3R1) that was strongly down-regulated (Hochet and Aspden, 2007). NHERF-1 acts with NHE-3 (sodium/hydrogen exchanger 3, SLC9A3) to regulate intracellular $\mathrm{pH}$ through control of sodium and potassium ion concentrations but is also shown to interact with PTEN (phosphatase and tensin homologue), a tumour suppressor, and to regulate cell proliferation in various cancers and cell types (Li et al., 2015; Molina et al., 2012; Takahashi et al., 2006). Immunofluorochemistry studies demonstrate cytoplasmic accumulation of NHERF-1, PTEN and $\beta$-catenin, consistent with increased AKT (also known as protein kinase B) activation and Wnt signalling due to the translocation of the $\beta$-catenin that has accumulated in the cytoplasm to the nucleus in both chondrocytes and osteoblasts from OA femoral heads (Griffin-Walker et al., 2017; White et al., 2015). A similar translocation was found from cell membrane to the cytoplasm for NHERF-1 to that which is reported in tumour growth, supporting its possible role in hyperplasia (Griffin-Walker et al., 2017).

\section{Obesity and adipose tissue}

There is a recognised association between being overweight and OA of knees, hips and hands (Issa and Griffin, 2012; Reyes et al., 2016; Thijssen et al., 2014). Is this mechanical or metabolic, or both? Being overweight is known to predate the incidence of disease (Felson et al., 2000). Results from both the Chingford and the Framingham studies show that body mass index (BMI) is linked to all patterns of knee OA (Cooper et al., 1996; Felson et al., 1988; Hart et al., 1995). Mechanical overloading is the obvious mechanism for subsequent cartilage degeneration. This may play a role in knee and hip OA but much harder to understand in OA of the hand, where baseline obesity is associated with the incidence of hand OA 23 years later (Carman et al., 1994). A growing literature is increasingly pointing away from a simple link between mechanical overloading and OA. Or, conversely, that obesity is a consequence of reduced activity due to joint pain. The role of adipose tissue as an endocrine organ secreting adipokines is increasingly prevalent (Aspden, 2011; Berenbaum and Sellam, 2008; Francisco et al., 2018; Issa and Griffin, 2012; Pottie et al., 2006; Reyes et al., 2016; Thijssen et al., 2014). The association between OA and being overweight is strongest with incidence and severity but not with progression. This is shown clearly in a study that recruited morbidly obese women (body mass index (BMI) between 30 and 50 $\mathrm{kg} / \mathrm{m}^{2}$ ), on the basis that they would progress fastest and enable a therapeutic approach to be tested most rapidly (Hellio Le Graverand et al., 2009). Joint space narrowing does not increase with BMI and they conclude that there is nothing to be gained from using this measure by recruiting obese individuals.

Following observations that femoral heads recovered from OA patients, after total hip replacements, seem to contain much more fat than those from osteoporotic patients, the fat content and the fatty acid composition was measured (Plumb and Aspden, 2004). It was found that the bone cores from OA bone contained twice the mass of fat per unit volume of tissue as osteoporotic bone. The fat contained more (n-6) fatty acids, and the amount of arachidonic acid was double that found in the tissue from osteoporotic bone. These fatty acids are the substrates for the cyclo-oxygenase enzymes, that are the target of many non-steroidal antiinflammatory drugs, and result in the formation of prostaglandins - active pro-inflammatory mediators. Features of OA are suggested to have many similarities with atheromatous vascular disease (Marks and Allegrante, 2002) and the role of lipids in calcification is an active area of study in the formation of atherosclerotic plaques (Parhami et al., 2001), as well as the differentiation of stem cells into osteoblasts and adipocytes (Parhami et al., 1999). These systemic and metabolic markers indicate that OA may, therefore, be a part of the socalled Metabolic Syndrome (MetS). MetS has a very broad spectrum of included syndromes/diseases and includes obesity, hypercholesterolaemia, hyperlipidaemia, hypertension and cardiovascular disease as characterised by atherosclerotic plaques (Zhuo et al., 2012). However, a recent systematic review of the link between MetS and OA in different joints, by Li and Felson, indicates that there is no relationship with hip OA. The possible associations with hand and knee OA are not clear, due to limitations in the studies. These are reported to be small in participant numbers, mainly cross-sectional in nature with few outcome measures or adjustment for co-variates (Li and Felson, 2018). There is a growing understanding that cells of mesenchymal origin can not only be directed to differentiate down specific lineages, by soluble factors activating the relevant nuclear receptor, but also may be redirected by modulating the nature of their stem-cell niche. Hence, modulating the stem-cell precursors may affect all the cell lineages derived from those stem cells and, consequently, affect the composition and, therefore, the functionality of all the derived tissues. This knowledge begins to open new avenues for understanding why so many tissues are affected by the disease process and, perhaps, why adipose tissue is one of the key drivers of OA (Aspden, 2011). Genetic and epigenetic factors are shown to be transmitted through cell lineages. For example, re-expression of growth and development factor 5 $(G d f-5)$, is found in the synovium of mouse models 
of OA, with a role in cartilage repair. Also, a second gene, one of the bone morphogenetic factors Bmp-7, is shown to play a critical role in joint patterning (Roelofs et al., 2017).

\section{Synovial hyperplasia}

One aspect of osteoarthritis development which has received a significant amount of interest is synovial hyperplasia. A review by de Lange-Brokaar and colleagues uncovers 100 different papers that show different aspects of synovial hyperplasia in humans (de Lange-Brokaar et al., 2012). This includes investigations of synovial tissue proliferation, infiltration of the tissue by macrophages and - to a lesser extent - neutrophils, quantification of cytokines such as IL-1 $\beta$ and IL- 6 , the role of other immune cells such as T-cells and the degree of inflammation that is involved. A PubMed search using the terms "synovial hyperplasia" and "osteoarthritis" showed that there were over 200 papers on this particular topic, indicating the complexity of the synovial tissue and its role in OA pathophysiology. It is commonly believed that there is no inflammatory involvement in the development of OA. However, this view seems to have shifted to show that there are indeed low levels of inflammation present in many patients with OA, albeit at a lower level than is commonly associated with RA (Sokolove and Lepus, 2013). There are reports of increased levels of the cytokines IL-1 $\beta$ and TNF- $\alpha$ (tumour necrosis factor alpha) in cartilage matrices undergoing degeneration (Kapoor et al., 2010). Many papers highlight that in OA tissue there are increased features of hyperplasia, demonstrated by increased scores compared with normal tissue. The seminal work of Mankin, in developing a robust scoring system for the classification of hyperplasia and associated changes observed in OA (Mankin et al., 1981), cannot be overlooked and has been key in changing the mindset that the condition of the cartilage is the most critical pathophysiological change in OA development. This is reflected in the subsequent updates to the consensus OARSI scoring system (Pritzker et al., 2006).

\section{Other indicators of growth}

The joint capsule is a tough, strong tissue that not only contains the joint fluid but also plays a vital, and commonly under-estimated, role in the biomechanics of synovial joints. Capsular ligaments augment other ligaments to maintain joint stability (Ralphs and Benjamin, 1994). In OA there is progressive fibrosis of the capsule and of the ligaments, resulting in thickening and shortening of the tissue and a reduction in its flexibility (Lloyd-Roberts, 1953). Ruptures of the anterior cruciate ligament are found to be far more common in subjects with symptomatic knee OA (Hill et al., 2005). In patients, a history of knee injury is associated with increased radiographic OA (Johnson and Hunter, 2014). Although such an injury is a known risk factor for secondary OA, it cannot be determined which came first. However, there is evidence from the Osteoarthritis Initiative that loss of ACL integrity and the development of incident radiographic OA are not related (Johnson et al., 2015). It is possible, in some patients, that ligament damage arose after the onset of disease as a consequence of altered tissue biomechanical properties. Studies of OA in the STR/ort mouse show that cruciate ligament metabolism is upregulated before radiological signs are present and that the tissue is weaker than in controls (Anderson-MacKenzie et al., 1999; Staines et al., 2017).

The changes in quantity, appearance and viscosity of synovial fluid in OA are well documented but high numbers of mesenchymal precursor cells (mesenchymal stem cells (MSCs)) are reported in synovial fluid from OA patients (Jones et al., 2004). Because levels are higher than in RA, it is suggested that these are not simply a consequence of an inflammatory process. These cells are pluripotent, with their ultimate phenotype able to be manipulated by altering the chemical composition of the culture medium. They possess the ability to be differentiated in culture to three main cell types; osteoblasts, chondrocytes and adipocytes. The origin of the MSCs is currently unknown, but cells with stem-cell-like properties are being identified in most joint tissues (Franceschetti and De Bari, 2017). Multiplication of stem cells could have a key role in the underlying tissue hyperplasia being described here as well as in the return to a more developmental phenotype but their presence, and in what numbers, is still an active area of investigation. By better understanding the origin of these cells and the factors required to drive them to differentiate into specific cell lineages, a deeper explanation of why cells in OA tissue seem to revert to a more developmental phenotype may be gained.

Among many possible growth, genetic and epigenetic factors that associate with OA incidence and progression, two warrant special mention; so-called axon guidance molecules - because they are normally associated with development - and cartilage oligomeric matrix protein (COMP) - because it is widely used as a serum biomarker. In preliminary studies, using gene arrays, an approximately 2-fold higher expression of spondin-1 (F-spondin) was found in OA bone than in osteoporotic bone and further exploration revealed increased expression of neuropilin and semaphorins (unpublished). Another study reports a 7-fold increase in spondin-1 in human OA cartilage (Attur et al., 2009). These molecules are traditionally studied during embryonic development and are associated with growth of nerves into newly formed tissues. Studies in embryonic cartilage suggest that spondin- 1 has the capacity to enhance chondrocyte terminal differentiation and mineralisation through interactions in its thrombospondin-repeat domain 
and TGF-beta dependent pathways (Palmer et al., 2010). These studies provide supporting evidence for a recapitulation of developmental processes occurring in diseased tissues.

Finding biomarkers for OA is a high priority, as evaluating radiographic joint space - which requires imaging - is the only current biomarker accepted by the US Food and Drug Administration (FDA) and is not a very sensitive method. COMP is identified as a cartilage matrix protein (DiCesare et al., 1995) and it was soon recognised that its degradation in OA could reflect disease processes occurring in the matrix (DiCesare et al., 1996). Elevated levels of COMP are found in the serum of patients with OA and it is proposed as a biomarker for diagnosis and prognosis (Verma and Dalal, 2013). Much is reported of attempts to elucidate its roles within cartilage but, for the purposes of this review, of considerable interest is the finding that COMP is expressed in the apical ectodermal ridge (AER) of the human embryo at gestational week 8 , as well as in the cavitating joint at weeks 10 and 12 (Koelling et al., 2006). The AER is the starting point of limb formation and, hence, it appears to be a key player in the formation of the limbs. This is reinforced by another study in which COMP is found to be involved in the regulation of endochondral bone growth (Kong et al., 2010). Perhaps this makes it less surprising that elevated levels are found in OA joints, if there is a reversion to an earlier developmental phenotype.

\section{Infrapatellar fat pad}

The infrapatellar fat pad, located distally to the patella and the femur is shown to be a localised source of adipokines in OA as well as functioning as a buffering and lubricating tissue (Favero et al., 2017). Clockaerts et al. argue, in a narrative review of the area, that the infrapatellar fat pad should be considered to be an active $\mathrm{OA}$ tissue. This is due to the cytokines produced, the innervation which may be linked to OA pain, and the production of adipokines that inhibit the biosynthesis of cartilage matrix proteins (Clockaerts et al., 2010). In a subsequent paper, however, they show that conditioned media from the infrapatellar fat pad inhibited catabolic processes in the cartilage (BastiaansenJenniskens et al., 2012). Han and colleagues go a little further and start to speculate as to whether the role of fat localised to the joint area is a good or bad thing (Han et al., 2014). They show, in MRI-based studies, that there were several significant changes in the infrapatellar fat pad that had negative consequences for the development of OA, mainly related to volume, joint space narrowing and any involvement of bone marrow lesions. Clearly, the significant changes which are reported in the infrapatellar fat pad add to the idea of the joint being an organ. Another paper shows that inflamed infrapatellar fat pads are shown to be hyperintense on MRI scans of the knee. When correlated with structural changes, this is found to be associated with worsening of bone marrow lesions, a feature of OA pathology and more generalised joint damage (Jarraya et al., 2017).

\section{Joint shape and OA}

In addition to molecular events, the understanding of how anatomical features, such as joint shape, influence disease pathophysiology has evolved from simple gross observations. Malformation of a joint during development, e.g. developmental dysplasia of the hip, is a known risk-factor for later OA. However, more recently, it has been shown that less overt changes - often found associated with demanding sporting activities in adolescents - appear, at least in part, to underlie femoro-acetabular impingement - now recognised as a cause of later OA (reviewed by Pun et al., 2015). But what about more subtle variations in joint shape? Can these be measured and do any of the features identified relate to OA incidence or progression? It has been shown that the radiographic outline of the femoral head of patients with hip OA has a different shape from that of matched asymptomatic controls (Gregory et al., 2007) (Fig. 2). This shape can be quantified using Statistical Shape Modelling (SSM) (Cootes et al., 1995), which uses principal component analysis to describe the shape in terms of independent "modes of variation". Each image in a dataset then receives a score for each mode, which describes how many standard deviations it lies from the overall mean of all the images. Using radiographic images from the Rotterdam study, none of whom were symptomatic at baseline, it was found that a number of modes were significantly associated with OA severity six years later and those who progressed most rapidly to hip replacement could be identified as a sub-group (Gregory et al., 2007). Subsequently, using SSM from DXA (dual-energy x-ray absorptiometry) images, it was shown that measures of hip shape were associated with radiographic hip $\mathrm{OA}$, and to a lesser extent hip pain, in the MrOS (osteoporotic fractures in men) cohort (Faber et al., 2017). The method showed promise as an imaging biomarker, as it 


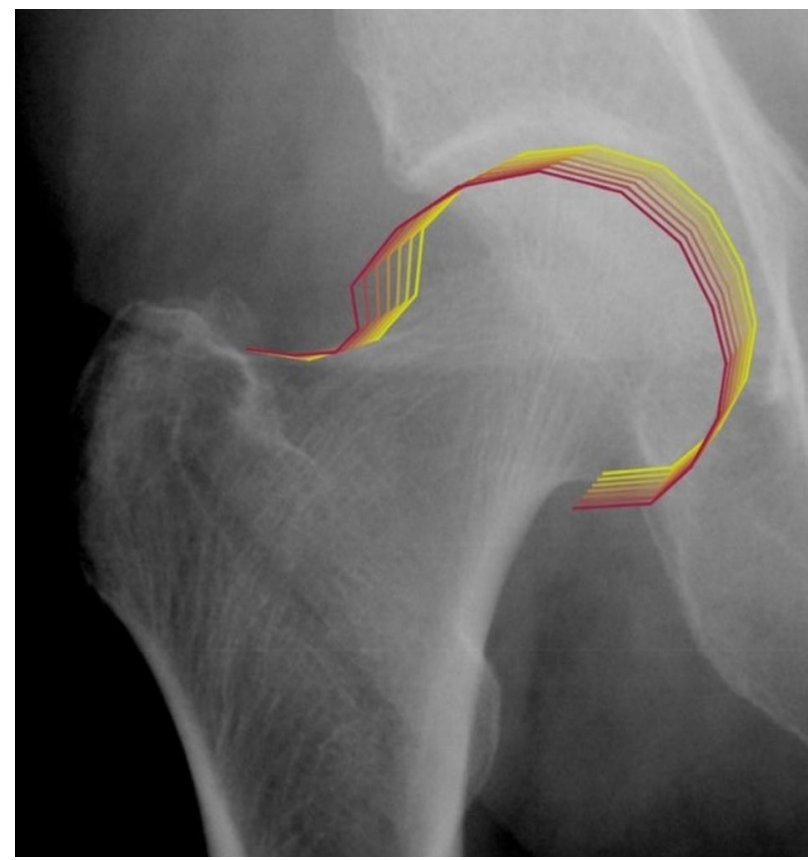

Fig. 2. Statistical shape model overlaid on a radiograph. The variation in shape over \pm 2 standard deviations is shown (from yellow to red) for this mode associated with OA.

was found that statistically significant changes could be measured in shape over a 12-month period in a small longitudinal cohort comprising 62 individuals (Barr et al., 2018). Using data from the MRC National Survey of Health and Development (a birth cohort all born in one week in 1946), it was found that life-course factors were associated with the shape of the hip and spine at age 60-64 years as determined by DXA imaging. Being overweight, especially greater gains in weight during life, were associated with a flatter femoral head and a shorter femoral neck (Muthuri et al., 2017). Other epidemiological studies, using the same cohort, show that knee $\mathrm{OA}$ is associated with high BMI throughout adult life (Wills et al., 2012) and that hand OA is associated not only with high BMI but also with low birth weight, but only in men (Sayer et al., 2003). Intriguingly, it has recently been found that age at first walking is associated with hip shape (Ireland et al., 2018) as well as with bone strength at the hip (Ireland et al., 2017). Using images from the ALSPAC (Avon Longitudinal Study of Parents and Children) cohort, the association of genes already identified as related to OA with hip shape modes was explored and several susceptibility loci were found, including KLHDC5-PTHLH (Kelch-like family member 5-parathyroid-like hormone), DOT1L (DOT-1 like methyltransferase) and COL11A1 (Collagen
11Alpha1) (Baird et al., 2018). Combining these data with those from other cohorts, using a metaanalysis, has identified 8 SNPs independently associated with hip shape and, curiously, many of them were strongly related to the process of endochondral bone formation (Baird et al., 2018b). Studies of SSM in the Tasmanian Older Adult cohort (TASOAC), with multiple imaging modalities, had several modes of variation determined by SSM that were associated not only with radiographic hip OA, hip cartilage volume and muscle strength but also with pain and effusion-synovitis (Ahedi et al., 2017). Further analysis of these data has shown that hip shape as defined by SSM is also a predictor for the risk of total hip replacement (Mezhov et al., 2018).

\section{Conclusions and clinical implications}

Evidence is mounting that $\mathrm{OA}$ is an organ disease affecting the whole joint and its component tissues (Fig. 3). Changes in muscle, nerves and pain sensitivity, ligaments and the vascular system have all been documented and were reviewed previously (Aspden, 2008). The working hypothesis is that generalised $\mathrm{OA}$ affects the whole musculoskeletal system because it arises from renewed, dysregulated, growth of tissues derived largely from cells from the mesenchymal lineage. The particular joint or joints affected may then be determined by subtle biomechanical factors such as joint shape. Evidence suggests a reversion of the phenotype of their constituent cells to an earlier developmental stage that results in:

- faster turnover and hyperplasia of bone,

- increased adiposity leading to obesity,

- fibrosis of ligaments and joint capsule,

- altered muscle phenotype possibly including fat deposition and muscle weakness,

- proliferation of cartilage chondrocytes,

- increased matrix synthesis, but not incorporation, all leading to weakened tissue and mechanical breakdown. Identifying alterations in mesenchymal stem cells and their niches may provide new insights into the proliferation of these tissues. The particular joints affected most may be dependent on local biomechanical factors and statistical shape modelling is beginning to suggest there may be subtle variations in hip shape that act throughout the life-course. However, the underlying disease, it is believed, is metabolic and systemic (Aspden et al., 2001). Some of these pathological changes have been recognised before and the Oxford surgeon Josep Trueta commented, "The osteoarthritic process thus appears to be an attempt to transform a decaying joint into a youthful one" (Harrison et al., 1953). After half a century of focussing on articular cartilage, to 


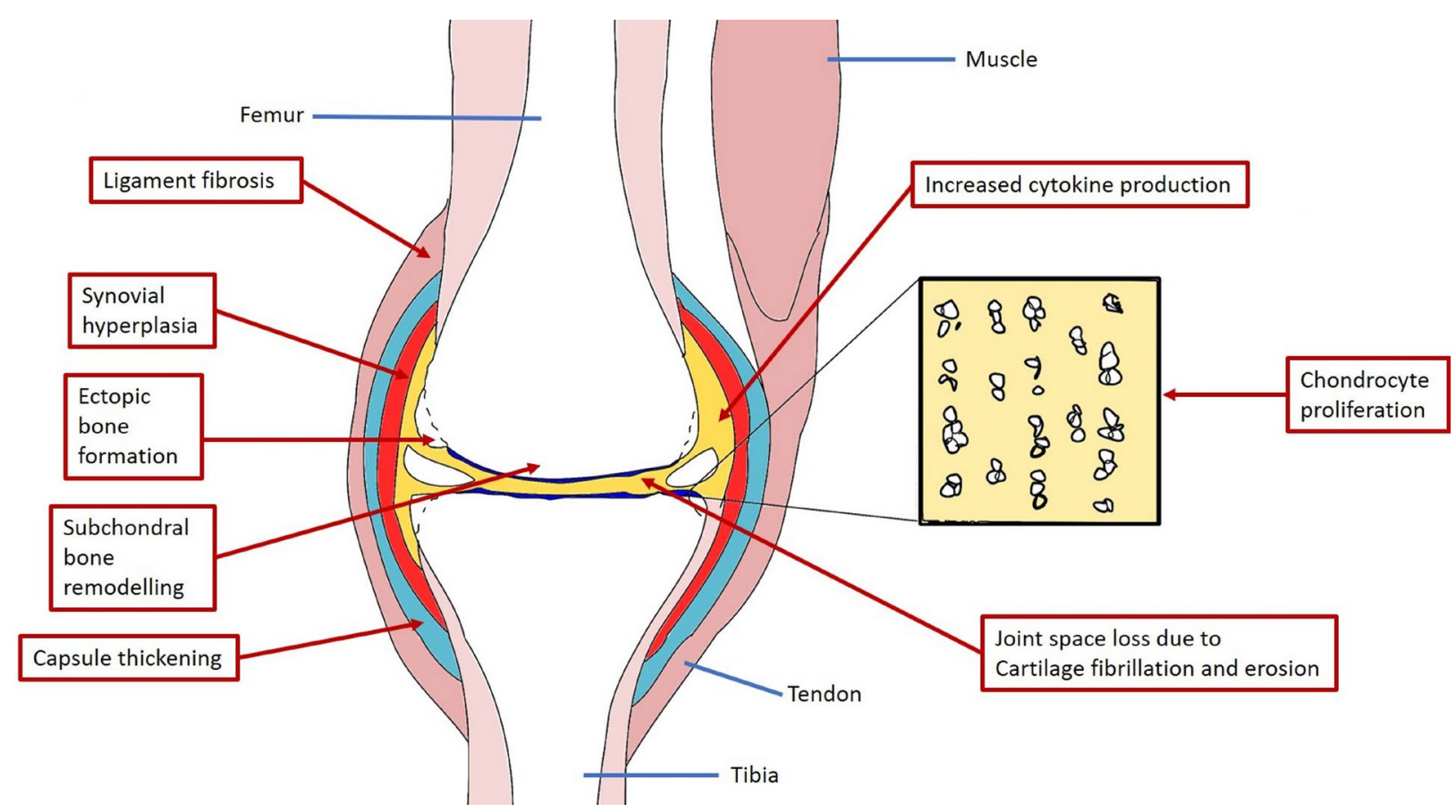

Fig. 3. Schematic drawing of an idealised synovial joint indicting some of the tissue changes discussed and showing why $\mathrm{OA}$ is a whole joint disorder. (Modified from an original drawing courtesy of Dr Anna Riemen, PhD thesis, 2018, University of Aberdeen).

the almost complete exclusion of other joint tissues, there is a returning again to the idea of OA as a joint disorder and a beginning to the understanding that processes throughout our life-course, from the cradle to the grave, may play a role in the pathogenesis of OA. A renewed focus on bone and the soft tissues of the joint in tandem with the cartilage will give a much more balanced picture of subtle changes that characterise OA.

These observations have many clinical implications. It becomes essential to identify OA in its early stages, especially those who are going to progress most rapidly (Gregory et al., 2007). Such methods and the resulting biomarkers are also essential for the development and effective testing of Disease Modifying OA drugs (DMOADs) in relatively short periods of time. Identifying circulating or urinary factors, or combinations of factors, deriving from tissues other than cartilage, such as bone, muscle or fat, may also provide new biomarkers of disease. Better still, a combination or panel of biomarkers, circulating, excretory and imaging, may harness better the markers we already know and provide a more sensitive measure of progression. It is believed that tissue engineering approaches to cartilage repair in osteoarthritis are almost certain not to succeed, at least in the short to medium term. If the natural tissue has been destroyed and the underlying problem has not been addressed, what chance is there for implanted tissue to survive, especially as, at least initially, the engineered tissue is commonly biomechanically inferior to the original? The exception would be local repair of damaged cartilage following trauma where it may be possible, with the correct combination of mechanical and biochemical cues, to engineer a tissue replacement that would be strong enough and could integrate with the existing tissue.

\section{Acknowledgements}

We thank all the members, past and present, of the Orthopaedics Research Group whose work forms our contribution to the quest for a solution to this most disabling disease. We also wish to thank all our surgical colleagues in NHS Grampian who have kindly allowed us to use tissue donated by their patients and provided many stimulating clinical insights. We are grateful to the Medical Research Council, the Arthritis Research Campaign, the Engineering and Physical Sciences Research Council, the Sir Halley Stewart Trust and The Health Foundation for funding research related to this work. We acknowledge grant funding from TMRI Ltd. for some of the SSM studies.

\section{References}

Ahedi HG, Aspden RM, Blizzard LC, Saunders FR, Cicuttini FM, Aitken DA, Jones G, Gregory JS (2017) Hip shape as a predictor of osteoarthritis progression in a prospective population cohort. Arthritis Care Res (Hoboken) 69: 1566-1573. 
Aigner T, Gluckert K, von der Mark K (1997) Activation of fibrillar collagen synthesis and phenotypic modulation of chondrocytes in early human osteoarthritic cartilage lesions. Osteoarthritis Cartilage 5: 183-189.

Aigner T, Zhu Y, Chansky HH, Matsen FA 3rd, Maloney WJ, Sandell LJ (1999) Reexpression of type IIA procollagen by adult articular chondrocytes in osteoarthritic cartilage. Arthritis Rheum 42: 14431450.

Anderson-MacKenzie JM, Billingham ME, Bailey AJ (1999) Collagen remodeling in the anterior cruciate ligament associated with developing spontaneous murine osteoarthritis. Biochem Biophys Res Commun 258: 763-767.

Arden N, Nevitt MC (2006) Osteoarthritis: epidemiology. Best Pract Res Clin Rheumatol 20: 3-25.

Aspden RM (1994) Fibre reinforcing by collagen in cartilage and soft connective tissues. Proc Biol Sci 258: 195-200.

Aspden RM (2008) Osteoarthritis: a problem of growth not decay? Rheumatology (Oxford) 47: 14521460.

Aspden RM (2011) Obesity punches above its weight in osteoarthritis. Nat Rev Rheumatol 7: 65-68.

Aspden RM, Hukins DWL (1981) Collagen organisation in articular cartilage determined by X-ray diffraction and its relationship to tissue function. Proc R Soc Lond B Biol Sci 212: 299-304.

Aspden RM, Scheven BAA, Hutchison JD (2001) Osteoarthritis as a systemic disorder including stromal cell differentiation and lipid metabolism. Lancet 357: 1118-1120.

Attur MG, Palmer GD, Al-Mussawir HE, Dave M, Teixeira CC, Rifkin DB, Appleton CT, Beier F, Abramson SB (2009) F-spondin, a neuroregulatory protein, is up-regulated in osteoarthritis and regulates cartilage metabolism via TGF-beta activation. FASEB J 23: 79-89.

Baird DA, Paternoster L, Gregory JS, Faber BG, Saunders FR, Giuraniuc CV, Barr RJ, Lawlor DA, Aspden RM, Tobias JH (2018a) Investigation of the relationship between susceptibility loci for hip osteoarthritis and dual X-ray absorptiometryderived hip shape in a population-based cohort of perimenopausal women. Arthritis Rheumatol 70: 1984-1993.

Baird DA, Evans DS, Kamanu FK, Gregory JS, Saunders FR, Giuraniuc CV, Barr RJ, Aspden RA, Jenkins D, Kiel DP, Orwoll ES, Cummings SR, Lane NE, Mullin BH, Williams FMK, Richards JB, Wilson S, Spector TD, Faber BG, Lawlor DA, Grundberg E, Ohlsson C, Pettersson-Kymmer U, Beck TJ, Evans DM, Paternoster L, Karasik D, Tobias JH. (2018b) Identification of novel loci associated with hip shape: a meta-analysis of genome-wide association studies. J Bone Miner Res. doi: 10.1002/jbmr.3605

Barr RJ, Gregory JS, Yoshida K, Alesci S, Aspden RM, Reid DM (2018) Significant morphological change in osteoarthritic hips identified over 6-12 months using statistical shape modelling. Osteoarthritis Cartilage 26: 783-789.

Bastiaansen-Jenniskens YM, Clockaerts S, Feijt C, Zuurmond AM, Stojanovic-Susulic V, Bridts C, de Clerck L, DeGroot J, Verhaar JA, Kloppenburg M, van Osch GJ (2012) Infrapatellar fat pad of patients with end-stage osteoarthritis inhibits catabolic mediators in cartilage. Ann Rheum Dis 71: 288-294.

Berenbaum F, Sellam J (2008) Obesity and osteoarthritis: what are the links? Joint Bone Spine 75: 667-668.

Bonde HV, Talman ML, Kofoed H (2005) The area of the tidemark in osteoarthritis--a three-dimensional stereological study in 21 patients. APMIS 113: 349352.

Buckland-Wright JC, Macfarlane DG, Lynch JA (1995) Sensitivity of radiographic features and specificity of scintigraphic imaging in hand osteoarthritis. Rev Rhum Engl Ed 62: 14S-26S.

Burgin LV, Edelsten L, Aspden RM (2014) The mechanical and material properties of elderly human articular cartilage subject to impact and slow loading. Med Eng Phys 36: 226-232.

Burr DB, Utreja A (2018) Editorial: Wnt signaling related to subchondral bone density and cartilage degradation in osteoarthritis. Arthritis Rheumatol 70: 157-161.

Carman WJ, Sowers M, Hawthorne VM, Weissfeld LA (1994) Obesity as a risk factor for osteoarthritis of the hand and wrist: a prospective study. Am J Epidemiol 139: 119-129.

Carrino JA, Blum J, Parellada JA, Schweitzer ME, Morrison WB (2006) MRI of bone marrow edemalike signal in the pathogenesis of subchondral cysts. Osteoarthritis Cartilage 14: 1081-1085.

Catterall JB, Zura RD, Bolognesi MP, Kraus VB (2016) Aspartic acid racemization reveals a high turnover state in knee compared with hip osteoarthritic cartilage. Osteoarthritis Cartilage 24: 374-381.

Clockaerts S, Bastiaansen-Jenniskens YM, Runhaar J, Van Osch GJVM, Van Offel JF, Verhaar JAN, De Clerck LS, Somville J (2010) The infrapatellar fat pad should be considered as an active osteoarthritic joint tissue: a narrative review. Osteoarthritis Cartilage 18: 876-882.

Cooper C, Egger P, Coggon D, Hart DJ, Masud T, Cicuttini F, Doyle DV, Spector TD (1996) Generalized osteoarthritis in women: pattern of joint involvement and approaches to definition for epidemiological studies. J Rheumatol 23: 1938-1942.

Cootes TF, Taylor CJ, Cooper DH, Graham J (1995) Active shape models - their training and application. Comput Vis Image Underst 61: 38-59.

Corr M (2008) Wnt-beta-catenin signaling in the pathogenesis of osteoarthritis. Nat Clin Pract Rheumatol 4: 550-556.

Crema MD, Roemer FW, Zhu Y, Marra MD, Niu J, Zhang Y, Lynch JA, Javaid MK, Lewis CE, El-Khoury GY, Felson DT, Guermazi A (2010) Subchondral 
cystlike lesions develop longitudinally in areas of bone marrow edema-like lesions in patients with or at risk for knee osteoarthritis: detection with MR imaging--the MOST study. Radiology 256: 855-862.

Daubs BM, Markel MD, Manley PA (2006) Histomorphometric analysis of articular cartilage, zone of calcified cartilage, and subchondral bone plate in femoral heads from clinically normal dogs and dogs with moderate or severe osteoarthritis. Am J Vet Res 67: 1719-1724.

de Lange-Brokaar BJE, Ioan-Facsinay A, van Osch GJVM, Zuurmond AM, Schoones J, Toes REM, Huizinga TWJ, Kloppenburg M (2012) Synovial inflammation, immune cells and their cytokines in osteoarthritis: a review. Osteoarthritis Cartilage 20: 1484-1499.

Dean D, Seog J, Ortiz C, Grodzinsky AJ (2003) Molecular-level theoretical model for electrostatic interactions within polyelectrolyte brushes: applications to charged glycosaminoglycans. Langmuir 19: 5526-5539.

Dedrick DK, Goldstein SA, Brandt KD, O'Connor BL, Goulet RW, Albrecht M (1993) A longitudinal study of subchondral plate and trabecular bone in cruciate deficient dogs with osteoarthritis followed up for 54 months. Arthritis Rheum 36: 1460-1467.

Dequeker J, Mokassa L, Aerssens J, Boonen S (1997) Bone density and local growth factors in generalized osteoarthritis. Microsc Res Tech 37: 358371.

DiCesare PE, Carlson CS, Stolerman ES, Hauser N, Tulli H, Paulsson M (1996) Increased degradation and altered tissue distribution of cartilage oligomeric matrix protein in human rheumatoid and osteoarthritic cartilage. J Orthop Res 14: 946-955.

DiCesare PE, Morgelin M, Carlson CS, Pasumarti S, Paulsson M (1995) Cartilage oligomeric matrix protein: isolation and characterization from human articular cartilage. J Orthop Res 13: 422-422.

Dobson GP, Letson HL, Grant A, McEwen P, Hazratwala K, Wilkinson M, Morris JL (2018) Defining the osteoarthritis patient: back to the future. Osteoarthritis Cartilage 26: 1003-1007.

Faber BG, Baird D, Gregson CL, Gregory JS, Barr RJ, Aspden RM, Lynch J, Nevitt MC, Lane NE, Orwoll E, Tobias JH, Osteoporotic Fractures in Men (MrOS) Study Research Group (2017) DXA-derived hip shape is related to osteoarthritis: findings from in the MrOS cohort. Osteoarthritis Cartilage 25: 2031-2038.

Favero M, El-Hadi H, Belluzzi E, Granzotto M, Porzionato A, Sarasin G, Rambaldo A, Iacobellis C, Cigolotti A, Fontanella CG (2017) Infrapatellar fat pad features in osteoarthritis: a histopathological and molecular study. Rheumatology (Oxford) 56: 1784-1793.

Felson DT, Anderson JJ, Naimark A, Walker AM, Meenan RF (1988) Obesity and knee osteoarthritis. The Framingham Study. Ann Intern Med 109: 18-24.

Felson DT, Lawrence RC, Dieppe PA, Hirsch R, Helmick CG, Jordan JM, Kington RS, Lane NE, Nevitt MC, Zhang Y, Sowers M, McAlindon T,
Spector TD, Poole AR, Yanovski SZ, Ateshian G, Sharma L, Buckwalter JA, Brandt KD, Fries JF (2000) Osteoarthritis: new insights. Part 1: the disease and its risk factors. Ann Intern Med 133: 635-646.

Franceschetti T, De Bari C (2017) The potential role of adult stem cells in the management of the rheumatic diseases. Ther Adv Musculoskelet Dis 9: 165-179.

Francisco V, Pérez T, Pino J, López V, Franco E, Alonso A, Gonzalez-Gay MA, Mera A, Lago F, Gómez R, Gualillo O (2018) Biomechanics, obesity, and osteoarthritis. The role of adipokines: When the levee breaks. J Orthop Res 36: 594-604.

Garrod AE (1907) Rheumatoid arthritis, osteoarthritis, arthritis deformans. In: A System of Medicine (Albutt TC, Rolleston HD, eds), Macmillan \& Co, London, pp 3-43.

Gelse K, Soder S, Eger W, Diemtar T, Aigner T (2003) Osteophyte development--molecular characterization of differentiation stages. Osteoarthritis Cartilage 11: 141-148.

Gevers G, Dequeker J, Geusens P, Nyssen-Behets C, Dhem A (1989a) Physical and histomorphological characteristics of iliac crest bone differ according to the grade of osteoarthritis at the hand. Bone 10: 173177.

Gevers G, Dequeker J, Martens M, Van AR, Nyssen-Behets C, Dhem A (1989b) Biomechanical characteristics of iliac crest bone in elderly women according to osteoarthritis grade at the hand joints. J Rheumatol 16: 660-663.

Goldring MB (2000a) Osteoarthritis and cartilage: the role of cytokines. Curr Rheumatol Rep 2: 459-465.

Goldring MB (2000b) The role of the chondrocyte in osteoarthritis. Arthritis Rheum 43: 1916-1926.

Goldring MB, Goldring SR (2007) Osteoarthritis. J Cell Physiol 213: 626-634.

Gregory JS, Waarsing JH, Day JS, Pols HA, Reijman M, Weinans H, Aspden RM (2007) Early identification of radiographic osteoarthritis of the hip using an active shape model to quantify changes in bone morphometric features: Can hip shape tell us anything about the progression of osteoarthritis? Arthritis Rheum 56: 3634-3643.

Griffin-Walker TG, McKenna KJ, Blair MC, Samy D, White R, Saunders FR, Aspden RM (2017) The roles of NHERF-1 and AKT in osteoarthritis. Osteoarthritis Cartilage 25: S153.

Guilak F, Meyer BC, Ratcliffe A, Mow VC (1994) The effects of matrix compression on proteoglycan metabolism in articular cartilage explants. Osteoarthritis Cartilage 2: 91-101.

Han W, Cai S, Liu Z, Jin X, Wang X, Antony B, Cao Y, Aitken D, Cicuttini F, Jones G, Ding C (2014) Infrapatellar fat pad in the knee: is local fat good or bad for knee osteoarthritis? Arthritis Res Ther 16: R145.

Harrison MHM, Schajowicz F, Trueta J (1953) Osteoarthritis of the hip: a study of the nature and evolution of the disease. J Bone Joint Surg Br 35-B: 598-626. 
Hart DJ, Doyle DV, Spector TD (1995) Association between metabolic factors and knee osteoarthritis in women: the Chingford Study. J Rheumatol 22: 11181123.

Haugen IK, Englund M, Aliabadi P, Niu J, Clancy M, Kvien TK, Felson DT (2011) Prevalence, incidence and progression of hand osteoarthritis in the general population: the Framingham Osteoarthritis Study. Ann Rheum Dis 70: 1581-1586.

Havdrup T, Hulth A, Telhag H (1976) The subchondral bone in osteoarthritis and rheumatoid arthritis of the knee. A histological and microradiographical study. Acta Orthop Scand 47: 345-350.

Hayes AJ, Smith SM, Caterson B, Melrose J (2018) Concise review: stem/progenitor cell proteoglycans decorated with 7-D-4, 4-C-3, and 3-B-3(-) chondroitin sulfate motifs are morphogenetic markers of tissue development. Stem Cells 36: 1475-1486.

Heinegard D, Saxne T (2011) The role of the cartilage matrix in osteoarthritis. Nat Rev Rheumatol 7: 50-56.

Heinemeier KM, Schjerling P, Heinemeier J, Moller MB, Krogsgaard MR, Grum-Schwensen T, Petersen MM, Kjaer M (2016) Radiocarbon dating reveals minimal collagen turnover in both healthy and osteoarthritic human cartilage. Sci Transl Med 8: 346ra390.

Hellio Le Graverand MP, Brandt K, Mazzuca SA, Raunig D, Vignon E (2009) Progressive increase in body mass index is not associated with a progressive increase in joint space narrowing in obese women with osteoarthritis of the knee. Ann Rheum Dis 68: 1734-1738.

Hill CL, Seo GS, Gale D, Totterman S, Gale ME, Felson DT (2005) Cruciate ligament integrity in osteoarthritis of the knee. Arthritis Rheum 52: 794799.

Hochet X, Aspden RM (2007) Wnt signalling in bone in osteoarthritis and osteoporosis. J Bone Miner Res 22: 1141-1141.

Hukins DWL, Aspden RM, Yarker YE (1984) Fibre reinforcement and mechanical stability in articular cartilage. Eng Med. 13: 153-156.

Ireland A, Muthuri S, Rittweger J, Adams JE, Ward KA, Kuh D, Cooper R (2017) Later age at onset of independent walking is associated with lower bone strength at fracture-prone sites in older men. J Bone Miner Res 32: 1209-1217.

Ireland A, Saunders FR, Muthuri SG, Pavlova AV, Hardy RJ, Martin KR, Barr RJ, Adams JE, Kuh D, Aspden RM, Gregory JS, Cooper R (2018) Age at onset of walking in infancy is associated with hip shape in early old age. J Bone Miner Res doi: 10.1002/ jbmr.3627.

Issa RI, Griffin TM (2012) Pathobiology of obesity and osteoarthritis: integrating biomechanics and inflammation. Pathobiol Aging Age Relat Dis 2: 17470.

Jarraya M, Guermazi A, Felson DT, Roemer FW, Nevitt MC, Torner J, Lewis CE, Stefanik JJ (2017) Is superolateral Hoffa's fat pad hyperintensity a marker of local patellofemoral joint disease? - The MOST study. Osteoarthritis Cartilage 25: 1459-1467.

Jeffrey JE, Aspden RM (2006) The biophysical effects of a single impact load on human and bovine articular cartilage. Proc Inst Mech Eng H 220: 677-686.

Jeffrey JE, Thompson LA, Aspden RM (1997) Matrix loss and synthesis following a single impact load on articular cartilage in vitro. Biochim Biophys Acta 1334: 223-232.

Johnson VL, Hunter DJ (2014) The epidemiology of osteoarthritis. Best Pract Res Clin Rheumatol. 28: 5-15.

Johnson VL, Kwoh CK, Guermazi A, Roemer F, Boudreau RM, Fujii T, Hannon MJ, Hunter DJ (2015) Loss of anterior cruciate ligament integrity and the development of radiographic knee osteoarthritis: a sub-study of the osteoarthritis initiative. Osteoarthritis Cartilage 23: 882-887.

Jones EA, English A, Henshaw K, Kinsey SE, Markham AF, Emery P, McGonagle D (2004) Enumeration and phenotypic characterization of synovial fluid multipotential mesenchymal progenitor cells in inflammatory and degenerative arthritis. Arthritis Rheum 50: 817-827.

Kapoor M, Martel-Pelletier J, Lajeunesse D, Pelletier J-P, Fahmi H (2010) Role of proinflammatory cytokines in the pathophysiology of osteoarthritis. Nat Rev Rheumatol 7: 33.

Klaassen Z, Tubbs RS, Apaydin N, Hage R, Jordan R, Loukas M (2011) Vertebral spinal osteophytes. Anat Sci Int 86: 1-9.

Koelling S, Clauditz TS, Kaste M, Miosge N (2006) Cartilage oligomeric matrix protein is involved in human limb development and in the pathogenesis of osteoarthritis. Arthritis Res Ther 8: R56.

Kong L, Tian Q, Guo F, Mucignat MT, Perris R, Sercu S, Merregaert J, Di Cesare PE, Liu C-j (2010) Interaction between cartilage oligomeric matrix protein and extracellular matrix protein 1 mediates endochondral bone growth. Matrix Biol 29: 276-286.

Larsson T, Aspden RM, Heinegård D (1991) Effects of mechanical load on cartilage matrix biosynthesis in vitro. Matrix 11: 388-394.

Lewis RJ, MacFarland AK, Anandavijayan S, Aspden RM (1998) Site variation of material properties and metabolic activity of articular cartilage from the bovine carpo-metacarpal joint. Osteoarthritis Cartilage 6: 383-392.

Li B, Aspden RM (1997a) Composition and mechanical properties of cancellous bone from the femoral head of patients with osteoporosis or osteoarthritis. J Bone Miner Res 12: 641-651.

Li B, Aspden RM (1997b) Mechanical and material properties of the subchondral bone plate from the femoral head of patients with osteoarthritis or osteoporosis. Ann Rheum Dis 56: 247-254.

Li B, Marshall D, Roe M, Aspden RM (1999) The electron microscope appearance of the subchondral bone plate in the human femoral head in osteoarthritis and osteoporosis. J Anat 195: 101-110. 
Li N, Qin J, Lan L, Zhang H, Liu F, Wu Z, Ni H, Wang Y (2015) PTEN inhibits macrophage polarization from M1 to M2 through CCL2 and VEGF-A reduction and NHERF-1 synergism. Cancer Biol Ther 16: 297-306.

Li S, Felson DT (2018) What is the evidence to support the association between metabolic syndrome and osteoarthritis? - a systematic review. Arthritis Care Res (Hoboken) doi: 10.1002/acr.23698.

Lippiello L, Walsh T, Fienhold M (1991) The association of lipid abnormalities with tissue pathology in human osteoarthritic articular cartilage. Metabolism 40: 571-576.

Lloyd-Roberts GC (1953) The role of capsular changes in osteoarthritis of the hip joint. J Bone Joint Surg Br 35-B: 627-642.

Loeser RF, Goldring SR, Scanzello CR, Goldring MB (2012) Osteoarthritis: A disease of the joint as an organ. Arthritis Rheum 64: 1697-1707.

Lohmander LS, Ionescu M, Jugessur H, Poole AR (1999) Changes in joint cartilage aggrecan after knee injury and in osteoarthritis. Arthritis Rheum 42: 534544.

Lorenzo P, Bayliss MT, Heinegard D (2004) Altered patterns and synthesis of extracellular matrix macromolecules in early osteoarthritis. Matrix Biol 23: 381-391.

Lories RJ, Luyten FP (2010) The bone-cartilage unit in osteoarthritis. Nat Rev Rheumatol 7: 43-49.

Luyten FP, Tylzanowski P, Lories RJ (2009) Wnt signaling and osteoarthritis. Bone 44: 522-527.

Mankin HJ, Johnson ME, Lippiello L (1981) Biochemical and metabolic abnormalities in articular cartilage from osteoarthritic human hips. III. Distribution and metabolism of amino sugarcontaining macromolecules. J Bone Joint Surg Am 63: 131-139.

Marks R, Allegrante JP (2002) Comorbid disease profiles of adults with end-stage hip osteoarthritis. Med Sci Monit 8: CR305-309.

Maroudas A (1976) Balance between swelling pressure and collagen tension in normal and degenerate cartilage. Nature 260: 808-809.

McCauley TR, Kornaat PR, Jee WH (2001) Central osteophytes in the knee: prevalence and association with cartilage defects on MR imaging. AJR Am J Roentgenol 176: 359-364.

Mezhov V, Laslett LL, Ahedi H, Blizzard L, Aspden RM, Gregory JS, Saunders F, Graves S, Lorimer M, Munugoda I, Cicuttini F, Jones G (2018) Predictors of total hip replacement: data from the Tasmanian older adult cohort stu. Intern Med J 48: 11.

Molina JR, Agarwal NK, Morales FC, Hayashi Y, Aldape KD, Cote G, Georgescu MM (2012) PTEN, NHERF1 and PHLPP form a tumor suppressor network that is disabled in glioblastoma. Oncogene 31: 1264-1274.

Muthuri SG, Saunders FR, Hardy RJ, Pavlova AV, Martin KR, Gregory JS, Barr RJ, Adams JE, Kuh D, Aspden RM, Cooper R (2017) Associations between body mass index across adult life and hip shapes at age 60 to 64: evidence from the 1946 British birth cohort. Bone 105: 115-121.

Nevitt MC, Lane NE, Scott JC, Hochberg MC, Pressman AR, Genant HK, Cummings SR (1995) Radiographic osteoarthritis of the hip and bone mineral density. The study of osteoporotic fractures research group. Arthritis Rheum 38: 907-916.

Oettmeier R, Abendroth K, Oettmeier S (1989) Analyses of the tidemark on human femoral heads. II. Tidemark changes in osteoarthrosis - a histological and histomorphometric study in non-decalcified preparations. Acta Morphol Hung 37: 169-180.

Page Thomas DP, King B, Stephens T, Dingle JT (1991) In vivo studies of cartilage regeneration after damage induced by catabolin/interleukin-1. Ann Rheum Dis 50: 75-80.

Palmer GD, Piton AH, Lwin MT, Oliviera SM, D'Angelo M, Attur MG, Abramson SB, Teixeira CC (2010) F-spondin regulates chondrocyte terminal differentiation and endochondral bone formation. J Orthop Res 28: 1323-1329.

Palmoski MJ, Brandt KD (1984) Effects of static and cyclic compressive loading on articular cartilage plugs in vitro. Arthritis Rheum 27: 675-681.

Parhami F, Jackson SM, Tintut Y, Le V, Balucan JP, Territo M, Demer LL (1999) Atherogenic diet and minimally oxidized low density lipoprotein inhibit osteogenic and promote adipogenic differentiation of marrow stromal cells. J Bone Miner Res 14: 2067-2078.

Parhami F, Tintut Y, Patel JK, Mody N, Hemmat A, Demer LL (2001) Regulation of vascular calcification in atherosclerosis. Z Kardiol. 90 Suppl 3: 27-30.

Patel V, Sema Issever A, Burghardt A, Laib A, Ries M, Majumdar S (2003) MicroCT evaluation of normal and osteoarthritic bone structure in human knee specimens. J Orthop Res 21: 6-13.

Plumb MS, Aspden RM (2004) High levels of fat and (n-6) fatty acids in cancellous bone in osteoarthritis. Lipids Health Dis. 3: 12.

Plumb MS, Aspden RM (2005) The response of elderly human articular cartilage to mechanical stimuli in vitro. Osteoarthritis Cartilage 13: 1084-1091.

Plumb MS, Treon K, Aspden RM (2006) Competing regulation of matrix biosynthesis by mechanical and IGF-1 signalling in elderly human articular cartilage in vitro. Biochim Biophys Acta 1760: 762-767.

Poole CA (1997) Articular cartilage chondrons: form, function and failure. J Anat 191: 1-13.

Pottie P, Presle N, Terlain B, Netter P, Mainard D, Berenbaum F (2006) Obesity and osteoarthritis: more complex than predicted! Ann Rheum Dis 65: 1403-1405.

Pritzker KPH, Gay S, Jimenez SA, Ostergaard K, Pelletier JP, Revell PA, Salter D, van den Berg WB (2006) Osteoarthritis cartilage histopathology: grading and staging. Osteoarthritis Cartilage 14: 1329.

Pun S, Kumar D, Lane NE (2015) Review: femoroacetabular impingement. Arthritis Rheumatol 67: 17-27. 
Radin EL, Burr DB, Caterson B, Fyhrie D, Brown TD, Boyd RD (1991) Mechanical determinants of osteoarthrosis. Semin Arthritis Rheum 21: 12-21.

Ralphs JR, Benjamin M (1994) The joint capsule: structure, composition, ageing and disease. J Anat 184: 503-509.

Reyes C, Leyland KM, Peat G, Cooper C, Arden NK, Prieto-Alhambra D (2016) Association between overweight and obesity and risk of clinically diagnosed knee, hip, and hand osteoarthritis: a population-based cohort study. Arthritis Rheumatol 68: 1869-1875.

Roelofs AJ, Zupan J, Riemen AHK, Kania K, Ansboro S, White N, Clark SM, De Bari C (2017) Joint morphogenetic cells in the adult mammalian synovium. Nat Commun 8: 15040.

Rojas FP, Batista MA, Lindburg CA, Dean D, Grodzinsky AJ, Ortiz C, Han L (2014) Molecular adhesion between cartilage extracellular matrix macromolecules. Biomacromolecules 15: 772-780.

Roughley PJ, Mort JS (2014) The role of aggrecan in normal and osteoarthritic cartilage. J Exp Orthop 1: 8 .

Sah RLY, Kim YJ, Doong JYH, Grodzinsky AJ, Plaas AHK, Sandy JD (1989) Biosynthetic response of cartilage explants to dynamic compression. J Orthop Res 7: 619-636.

Sayer AA, Poole J, Cox V, Kuh D, Hardy R, Wadsworth M, Cooper C (2003) Weight from birth to 53 years: a longitudinal study of the influence on clinical hand osteoarthritis. Arthritis Rheum 48: 10301033.

Scharstuhl A, Glansbeek HL, van Beuningen HM, Vitters EL, van der Kraan PM, van den Berg WB (2002) Inhibition of endogenous TGF-beta during experimental osteoarthritis prevents osteophyte formation and impairs cartilage repair. J Immunol 169: 507-514.

Seog J, Dean D, Plaas AHK, Wong-Palms S, Grodzinsky AJ, Ortiz C (2002) Direct measurement of glycosaminoglycan intermolecular interactions via high-resolution force spectroscopy. Macromolecules 35: 5601-5615.

Shen Z, Heinegard D, Sommarin Y (1995) Distribution and expression of cartilage oligomeric matrix protein and bone sialoprotein show marked changes during rat femoral head development. Matrix Biol 14: 773-781.

Sokolove J, Lepus CM (2013) Role of inflammation in the pathogenesis of osteoarthritis: latest findings and interpretations. Ther Adv Musculoskelet Dis 5: 77-94.

Staines KA, Poulet B, Wentworth DN, Pitsillides AA (2017) The STR/ort mouse model of spontaneous osteoarthritis - an update. Osteoarthritis Cartilage 25: 802-808.
Takahashi Y, Morales FC, Kreimann EL, Georgescu MM (2006) PTEN tumor suppressor associates with NHERF proteins to attenuate PDGF receptor signaling. EMBO J 25: 910-920.

Thijssen E, van Caam A, van der Kraan PM (2014) Obesity and osteoarthritis, more than just wear and tear: pivotal roles for inflamed adipose tissue and dyslipidaemia in obesity-induced osteoarthritis. Rheumatology (Oxford) 54: 588-600.

Thysen S, Luyten FP, Lories RJ (2015) Targets, models and challenges in osteoarthritis research. Dis Model Mech 8: 17-30.

van Beuningen HM, van der Kraan PM, Arntz OJ, van den Berg WB (1994) Transforming growth factorbeta 1 stimulates articular chondrocyte proteoglycan synthesis and induces osteophyte formation in the murine knee joint. Lab Invest 71: 279-290.

van der Kraan PM, van den Berg WB (2007) Osteophytes: relevance and biology. Osteoarthritis Cartilage 15: 237-244.

Verma P, Dalal K (2013) Serum cartilage oligomeric matrix protein (COMP) in knee osteoarthritis: a novel diagnostic and prognostic biomarker. J Orthop Res 31: 999-1006.

Wang Q, Zheng Y-P, Leung G, Lam WL, Guo X, Lu H, Qin L, Mak AF (2008) Altered osmotic swelling behavior of proteoglycan-depleted bovine articular cartilage using high frequency ultrasound. Phys Med Biol. 53: 2537.

Wheeler CA, Jafarzadeh SR, Rocke DM, Grodzinsky AJ (2009) IGF-1 does not moderate the time-dependent transcriptional patterns of key homeostatic genes induced by sustained compression of bovine cartilage. Osteoarthritis Cartilage 17: 944952.

White R, Blair MC, Saunders FR, Aspden RM (2015) The role of sodium hydrogen exchanger regulatory factor 1 in osteoarthritis. Osteoarthritis Cartilage 23: A134-A135.

Wills AK, Black S, Cooper R, Coppack RJ, Hardy R, Martin KR, Cooper C, Kuh D (2012) Life course body mass index and risk of knee osteoarthritis at the age of 53 years: evidence from the 1946 British birth cohort study. Ann Rheum Dis 71: 655-660.

Zhuo Q, Yang W, Chen J, Wang Y (2012) Metabolic syndrome meets osteoarthritis. Nat Rev Rheumatol 8: 729-737.

Editor's notes: There were no questions asked by reviewers for this paper therefore there is no Discussion with reviewers section. The Scientific Editor responsible for this paper was Martin Stoddart. 